\title{
LA RECONSTRUCCIÓN DEL PATIO DE LAS ARCAS DE LISBOA TRAS EL INCENDIO DE 1697*
}

\author{
Mercedes de los Reyes Peña \\ Piedad Bolaños Donoso
}

La independencia política de Portugal respecto a España, en 1640, no lleva aparejado el cese de la influencia cultural española, que continuará vigente en el reino vecino a lo largo de toda la centuria. En el ámbito dramático, la presencia de ese influjo es claramente manifiesta hasta bien entrado el siglo XVIII, pues hasta la década de 1730 no comienzan a sentirse con fuerza las influencias del teatro francés e italiano, que constreñirán, en parte, la total hegemonía de que había gozado el teatro español durante el seiscientos. La mejor prueba de esta hegemonía la ofrece el hecho de que, a pesar de la animadversión a los castellanos (explicable después de los sesenta años de anexión), cuando se reanuda en Lisboa la actividad teatral tras el tratado de paz que puso fin a las guerras de Restauración (1668), seguirán siendo españolas las compañías allí contratadas ${ }^{1}$ para actuar, con repertorios castellanos, en un lugar de representación -el Patio de las Arcas - construido, a imagen y semejanza de nuestros corrales de comedias, por un español avecindado en Lisboa, en la última década del siglo XVI ${ }^{2}$.

* Este trabajo forma parte de un estudio más amplio sobre el Patio de las Arcas, cuya historia estamos reconstruyendo en una investigación para la que hemos sido becadas por el Ministério da Educação e Ciência de Portugal, a través del Instituto de Cultura e Língua Portuguesa.

1 Para el período de 1640 a 1697, véase Piedad Bolaños Donoso y Mercedes de los Reyes Peña, «Presencia de comediantes españoles en el Patio de las Arcas de Lisboa (1640-1697)», en Actas del Simposio Internacional «El teatro español a fines del siglo XVII. Historia, Cultura y Teatro en la España de Carlos II» (Amsterdam, 6-10 de junio de 1988), en prensa.

2 Para la descripción del Patio de las Arcas a finales del seiscientos, estado que responde en líneas generales al aspecto que presentaba desde su creación por Fernando Díaz de la Torre, véase Mercedes de los Reyes Peña y Piedad Bolaños Donoso: «El Patio de las Arcas de Lisboa a finales del siglo XVII. Comparación con el corral castellano», en Idem. 
Pero aún hay más. Cuando, en 1700, se reedifica este local, después de haber sido totalmente destruido por un terrible incendio, el 10 de diciembre de 1697, su nueva fisonomía continuará siendo deudora en gran parte del modelo del corral castellano, sin incorporar, a pesar de lo avanzado de su fecha de reconstrucción, las conquistas del teatro italiano. Y es este nuevo estado del Patio de las Arcas, correspondiente a la última etapa de su vida, enmarcada entre 1697 — fecha del incendio- y 1755 - fecha de su desaparición con el terremoto-, el que describiremos en estas páginas. Para ello utilizaremos fundamentalmente dos documentos:

a) Una «receyta do que rendem as comedias», de 12 de abril de 1700 (Lisboa, Archivo del Hospital de San José, Livro de Receita, 1699-1700, fol. $244 \mathrm{r}^{\circ}$ ).

b) Un «auto de tombo de mediçaõ, deuizaõ e confrontaçaõ do $\mathrm{Pa}$ tio das Comedias com todas suas pertenças e cazas a fase da rua das Arquas, de que esta de posse o Hospital Real de Todos os Santos desta cidade, cito na freguesia de S. Justa», de mayo de 1707 (AHSJ, Maço 1. do Novo Tombo, Tombo dos Prazos do Hospital, 1, fols. 269 r. -284r., citado en adelante bajo las siglas NT), que incluye una escritura de «mediçaõ, deuisaõ e confrontaçaõ do prazo do Patio das Comedias», de 24 de mayo de 1707 (fols. 270 vo-283 vo), de la que, dada su naturaleza, nos serviremos prioritariamente ${ }^{3}$.

Pero antes de iniciar la descripción del Patio, conviene recordar que estaba situado, como se especifica en la escritura a la que acabamos de referirnos, «entre a rua das Arquas que he a que uai do Rosio pella rua da Prasa da Palha pera Saõ Nicolao, fiqua na entrada della, a parte esquerda, e entre o bequo das Comedias e o de Lopo Infante, o qual fiqua interior ao dito bequo das Comedias [...], uem fazer frente tudo na freguezia de Santa Justa» (NT, fol. 271r. $)^{4}$, en el plano de la antigua Lisboa (véase la lámina $\mathrm{I}^{5}$, donde hemos marcado el lugar del Patio con la letra P); y «pelo centro da Baixa, pouco mais ou menos no fim do segundo quarteirão da rua Augusta, vindo da praça de D. Pedro IV» en el trazado moderno de la ciudad, según la localización de Eduardo Freire de Oliveira ${ }^{6}$,

3 Esta escritura está transcrita de forma fragmentaria por José Maria António Nogueira, «Archeologia do theatro portuguez (1588-1762)», Jornal do Commercio, n. 3737, 6 de abril de 1866; José Gonçalves Ribeiro Guimarães, «Memorias para a historia dos theatros de Lisboa», Jornal do Commercio, n. 6585, 16 de octubre de 1875; y Theophilo Braga, Eschola de Gil Vicente e o desenvolvimento do theatro nacional, Porto, 1898, pp. 365-367. Los tres estudiosos recogen los mismos fragmentos, con la sola excepción de uno incluido por Ribeiro Guimarães que no citan ni Nogueira ni T. Braga.

4 Al transcribir respetamos al máximo la grafía del original. No obstante, para favorecer la lectura, desarrollamos las abreviaturas, subrayando las letras sobreentendidas en el original; seguimos el uso moderno en el empleo de las letras mayúsculas; puntuamos y separamos las palabras con criterios actuales; y ponemos siempre que es necesario la cedilla en ç $^{\mathrm{a} / \mathrm{o} / \mathrm{u}}$.

5 Fragmento de la «planta topográfica» de Lisboa realizada por João Nunes Tinoco, en 1650. Es la más antigua que se conoce de la ciudad y sólo por las copias que se sacaron del original (Cf. Augusto Vieira da Silva, Plantas topográficas de Lisboa, Lisboa, Câmara Municipal, 1950, p. 15).

6 En Elementos para a História do Municipio de Lisboa, t. III, Lisboa, Typographia Universal, 1887 , p. 40 , n. 1. Ya antes, 1875 , José Gonçalves Ribeiro Guimarães lo había ubicado en el mismo 


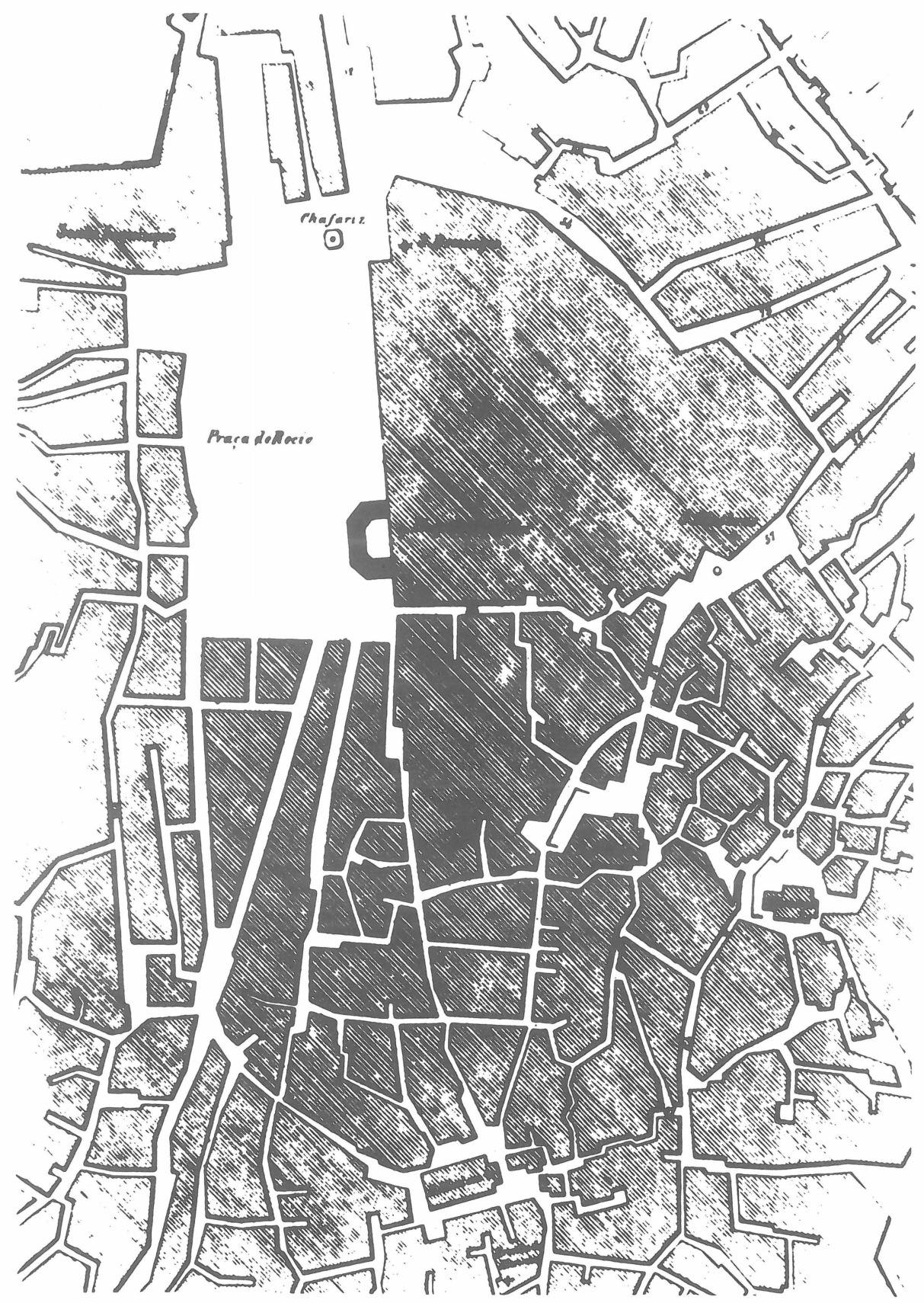

Lam. I. Fragmento de la «Planta da cidade de Lx. [...], delineada por Joaõ Nunes Tinoco, architecto de S. Mgde., anno 1650» (Fac-símile,Lisboa, Litg. da Imprensa Nacional, 1853. Archivo del Instituto Geográfico e Cadastral). 
que rectifica ligeramente Gustavo de Matos Sequeira, al radicarlo a la misma altura de la Praça do Rossio (D. Pedro IV) pero un poco más a la izquierda: «Quem passa hoje [1946] pela rua da Prata, entre as ruas de Santa Justa e da Assunção, pisa parte do Pátio que o quarteirão do lado Oriental engole dentro dos prédios pombalinos» ${ }^{7}$, localización esta última que compartimos (véase la lámina II, donde los nombres de las calles permiten, siguiendo a Matos Sequeira, situar el Patio en el plano de la moderna Lisboa; y la lámina III que posibilita ubicarlo sobre el antiguo y el moderno trazado de la ciudad ${ }^{8}$ ).

Después del incendio de 1697, el Hospital Real de Todos los Santos, que se auxiliaba de los ingresos del teatro para atender a los enfermos (recibía los 3/5 del rendimiento del Patio de las Arcas), decide comprar el Patio y sus derechos al que por entonces era su dueño, Antonio da Silva e Sousa, y emprender, convertido ya en propietario y único beneficiario, su reedificación. La transacción se realiza por escritura de 30 de junio de 1698 (NT, fols. 271ro-272vo ). Pero la Mesa de la Misericordia, administradora del Hospital, no se conformará con esta compra, sino que con el propósito de darle al Patio nueva orientación y forma, adquirirá, además, varias casas vecinas para unirlas a él, prolongándolo por el lado norte. Estas propiedades fueron: «as cazas de Manoel Gonsalues que hauiaõ sido estalagens, as quais estauaõ na dita rua das Arquas» ${ }^{9}$; "parte das cazas que tem [Dona Luiza Margarida de Andrade] na rua das Arquas, a parte do Norte, pera se allergar pera esta parte o uestuario dos comediantes que representaõ» 10; y «doce palmos de chaõ» que cedió el Marqués de Cascais en el «prazo que tinha que hauia sido de Antonio Gonzalues, vinhateiro, per outros tantos que o dito Hospital lhe deo pera dous camarotes que tem pera o dito patio donde se representaõ as comedias» ${ }^{11}$. Sin embargo, a pesar de estas adquisiciones, el Patio seguirá conservando aproximadamente sus dimensiones anteriores, aunque con un cambio de orientación: el tablado estará ahora al norte, de cara al sur, en vez de en la parte oriental, frente al poniente; y los lados más largos del rectángulo en el que el Patio continúa inscribiéndose, se hallarán, ahora, en dirección nortesur, en lugar de este-oeste, como ocurría en la etapa anterior (véase lámina IV).

La Mesa de la Misericordia otorga la superintendencia para la reconstrucción del Patio, «com noua estructura em perfeytissima forma», a los hermanos «Dom Fellipe de Souza, capitaõ da guarda», y a «Joseph Lopes, pedreyro»,

lugar: «pouco mais ou menos, onde hoje está o segundo quarteirão da rua Augusta» («Memorias para a historia dos theatros de Lisboa», Jornal do Commercio, n. 6585, 16 de octubre de 1875).

7 Gustavo de Matos Sequeira, «Os pátios de comédia e o teatro de cordel» en $A$ Evolução e o Espírito do Teatro em Portugal, Lisboa, Editorial Século, 1948-49. 2 vols., vol. I, pp. 221-254, p. 229.

8 Fragmento sacado de un plano sin título, ni firma, ni fecha (sólo tiene escrito a lápiz en la parte superior, en un cerco: Janeiro de 1786), como indica A. Vieira da Silva, que «contém, sobreposto à planta antiga da parte baixa arruinada de Lisboa, um projecto de reedifição da cidade, que diverge um pouco do que foi executado» (A. Vieira da Silva, Plantas topográficas de Lisboa, ob. cit., p. 20).

9 Por escritura de 5 de agosto de 1699 (NT, fol. 271rº).

10 Por escritura de 13 de enero de 1700. En este caso se especifica que no consta de la dicha escritura que hubiese «pagua em remunerasaõ [...], mas huma transausaõ e amigauel compozizam» (NT, fol. $272 v^{\circ}-273 r^{\circ}$.).

11 Por escritura de «transausaõ e amigauel compozisaõ, de 4 de octubre de 1699 (NT, fol. 273r.․). 


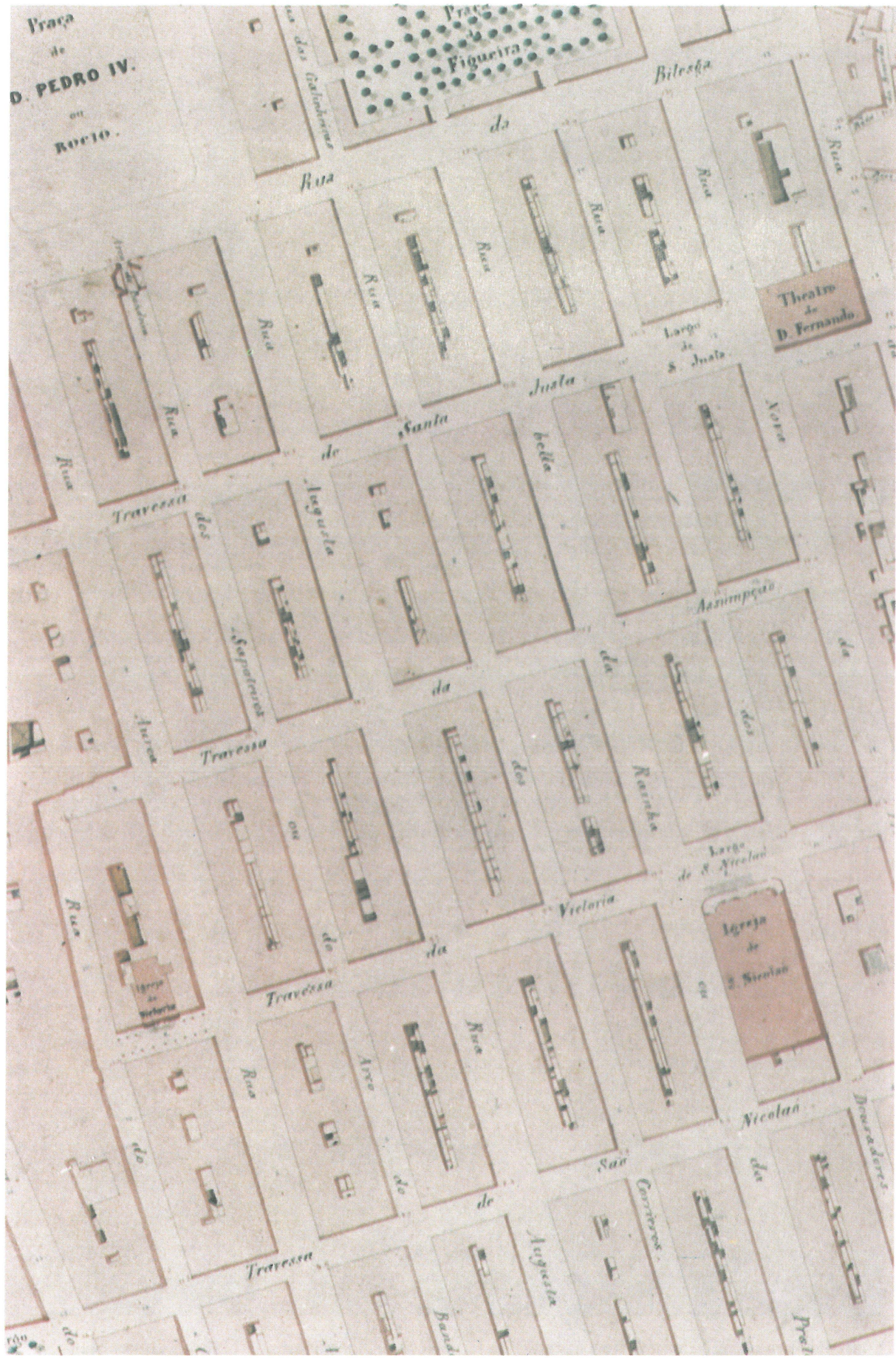

Lám. II. Fragmento de un plano de la Baixa Pombalina (Lisboa, Archivo del Instituto Geográfico e Cadastral, Carta antiga, n. 43). 


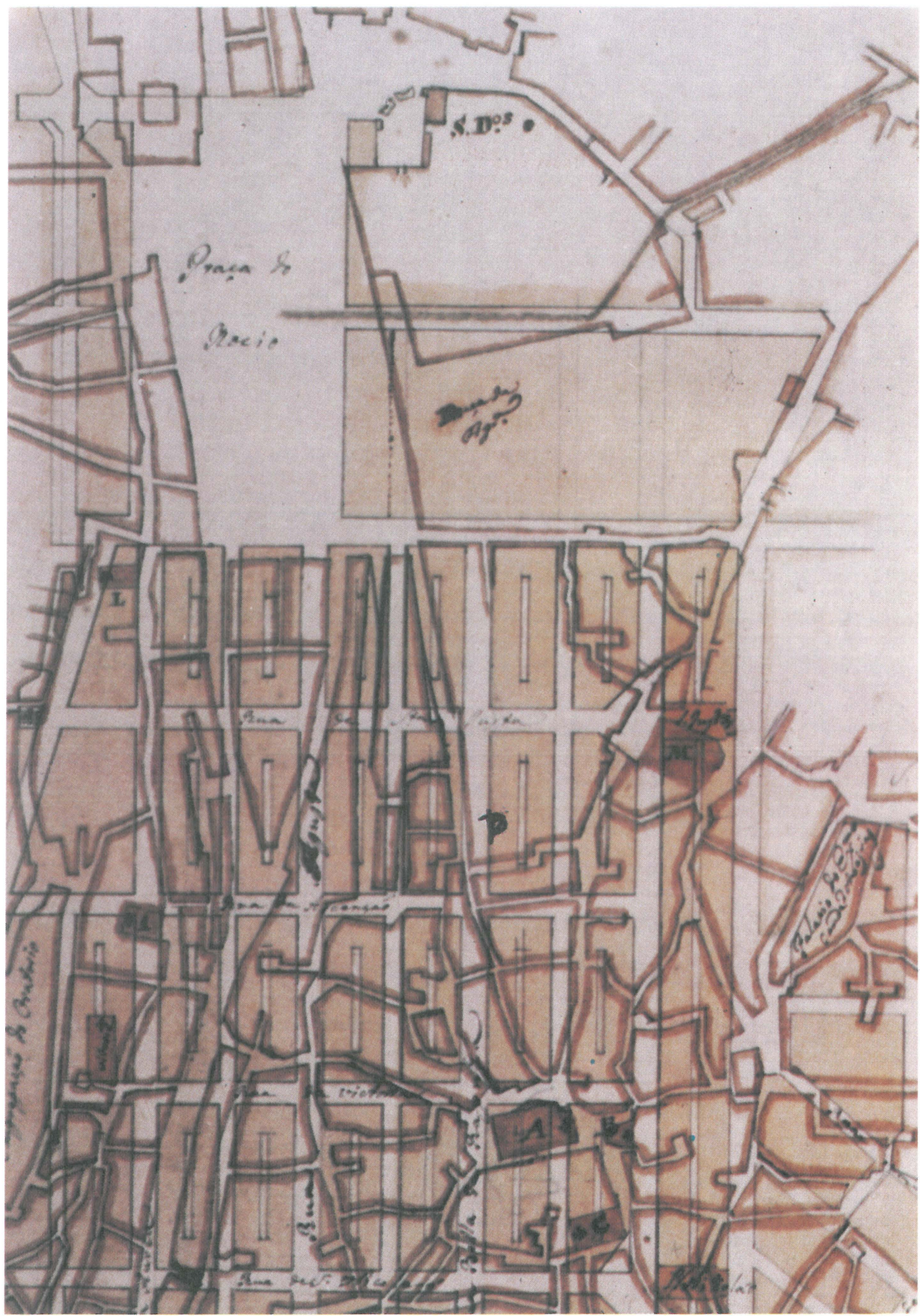

Lám. III. Fragmento de un plano antiguo de la parte baixa arruinada de Lisboa, con el plano sobrepuesto de su reconstrucción (Lisboa, Archivo del Instituto Geográfico e Cadastral, Carta antiga, n. 354. Hemos marcado el lugar en que se encontraba el Patio con la letra P). 


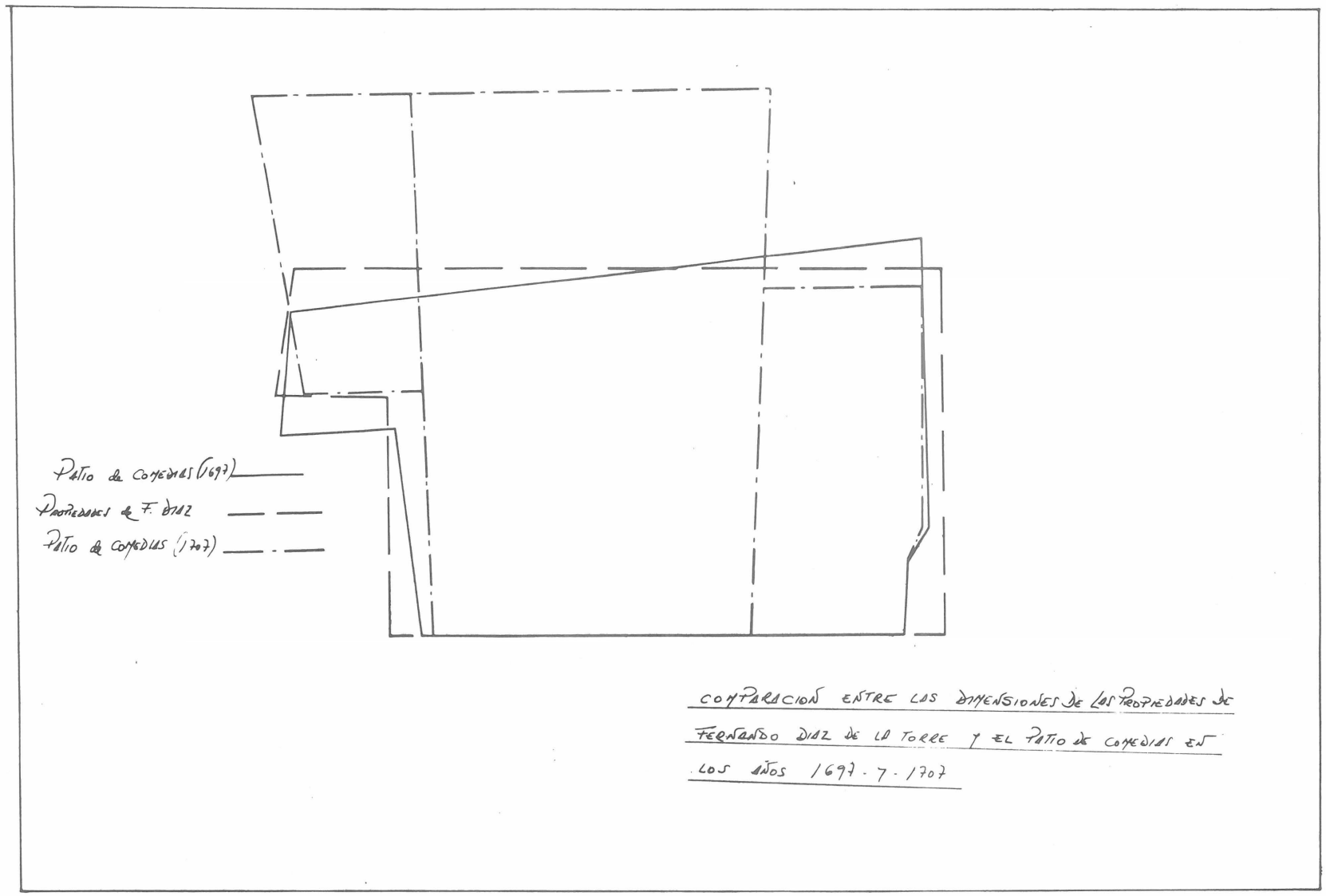

Lám. IV. Superposición de las superficies de las casas y «quintal» comprado por Fernando Díaz de la Torre, en 1593, para construir en éste el Patio de Comedias; de la de dichas casas y el Patio de Comedias en 1696 ó 1697, antes del incendio; y de la de las casas, el Patio de Comedias y un patio descubierto anexo, en 1707 . 
abriendo sus puertas tras su remodelación el 12 de abril de 1700, primera semana de Pascua (Livro de Receita, 1699-1700, fol. 244r.). . La magnificencia del nuevo estado del Patio queda hiperbólicamente de relieve en un romance que el Conde de Tarouca ${ }^{12}$ dedica al protector de la reedificación, D. Felipe de Sousa, que estimamos de gran interés por tratarse del testimonio de un contemporáneo, de un testigo de vista. He aquí algunos de sus versos más significativos a propósito de la descripción del Patio:

¡Vitor!, senhor Dom Felipe, porque por vos hoje esta de vinte e quatro alfinetes das comedias o corral.

Felicemente infelice ardeo no fogo voras, qual o ouro a quem aluma crece as seos quilates mais.

Entrei na comedia, adonde em ves da moeda real da bolça da admiraçaõ deu por dinheiro a pasmar. Pello molde dos arcos se debuxou tål galan que a materia he de madeira e a fineza de Cambraj. Os olhos contra os ouvidos se daõ batalha mental, porque aos ouvidos o oficio os olhos querem tirar. $\mathrm{O}$ patio narcizo em tudo cuja fermozura he tal que batalhaõ dous sentidos por ter com que verle mais. De meia laranja a forma de seos camarotes vaj, mas naõ de laranja azeda senaõ de laranja bical. Porque nelles para o gosto azedas cauzas naõ ha, que obrando tudo parece pellas maos do imaginar.

Propreamente o Pilicano pintado no patio esta,

12 João Gomes da Silva, 4. Conde de Tarouca (Lisboa, 1671-Viena, 1738). Escritor, militar y diplomático, fue ministro plenipotenciario de Portugal en el Congreso de Utrech (Cf. Diogo Barbosa Machado, Bibliotheca Lusitana, t. II, Coimbra, Atlântida Editora, 1966, pp. 671-673; e Innocencio Francisco da Silva, Diccionario Bibliographico Portuguez, t. III, Lisboa, Imprensa Nacional, 1859, pp. 381-382). 


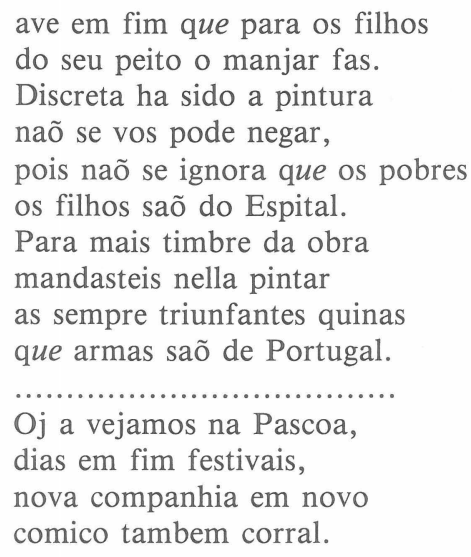

Para el Conde de Tarouca, el Patio, paradójicamente, gana con el incendio, pues sale de tan desgraciado evento muy subido de valor. Tras esta primera aproximación al recién inaugurado Patio de las Arcas a través de los ojos de un contemporáneo, iniciamos su reconstrucción con un acercamiento preciso y detallado a lo que fueron sus límites, dimensiones y estructura en esta nueva etapa, basándonos fundamentalmente en los datos contenidos en la escritura de 1707, ya citada.

\section{Linderos generales del Patio.}

En la escritura de 1707, el Patio de Comedias aparece integrado como parte principal en un conjunto de tres elementos diferenciados que constituyen la propiedad del Hospital de Todos los Santos, que se registra: el Patio de Comedias; un pequeño patio descubierto anexo a él por la parte oriental; y unas casas, también anexas, por el lado occidental, con fachada y salida a la rua das Arcas. A este conjunto tripartito corresponden los límites y la primera medición registrada en el tumbo, sólo después se especificarán por separado las dimensiones de cada uno de esos tres componentes. Atendiendo al conjunto, la propiedad del Hospital en la que se hallaba incluido el Patio de Comedias (como elemento central, repetimos) limitaba (véase lámina $\mathrm{V}$ ):

a) Por el Norte, con casas de D. Julliana (que fueron de D. Luiza Margarida de Andrade) y con casas del Marqués de Cascais con salida al Bêco de Lopo Infante, foreras del Hospital ( $N T$, fol. 274rº).

13 C. Tarouca, «A D. Fellipe de Souza, Protetor da redificaçaõ do Patio das Comedias», Biblioteca Nacional de Lisboa, Cod. 8632, fols. 183vํ-185ro. [numeración a lápiz]. 
b) Por el sur, con casas y «estalagens» que tenían la fachada y salida para el Bêco das Comedias y con otras que daban a la rua das Arcas. Propietarios de las primeras eran: Alexandre da Crux, D. Joseph de Menezes Tauera, Francisco Dias y Luis de Silueira; perteneciendo las últimas al platero Paullo Alues Brondaõ (NT, fol. 274r.).

c) Por el Este, con casas de Joseph Denis, foreras del Conde de Vila Nova; con casas que fueron de Joaõ da Costa, dentista; y con Antonio Montejro, sastre, todas con fachada y salida al Bêco de Lopo Infante (NT, fol. 274v? ).

d) Por el Oeste, con la rua das Arcas y con el «prazo» de Paullo Alues Brondaõ (NT, fol. 274v. $)$.

Como se puede apreciar, el Patio de Comedias continuaba, igual que en la etapa anterior, sin fachada a la calle y cercado por predios vecinos. No obstante, parte de su fachada oriental limitaba ahora con un patio descubierto que le pertenecía y que se encontraba ubicado en la zona que antiguamente ocupaban el tablado y el vestuario de los comediantes, pequeño patio éste rodeado también por propiedades vecinas. En el Tombo da Cidade de 1755, mandado hacer por el Marqués de Pombal tras el terremoto, al registrar las medidas «da caza que foy da comedia», se incluyen también las de dos estrechos corredores descubiertos que por el lado sur y parte del costado occidental separaban el Patio de las casas vecinas: «Vaõ que se metia entre a dita caza da comedia e as propriedades vizenhas da parte do beco da Comedia tem de comprimento do Leste pera Oeste, $82 \mathrm{p}$. e $1 / 2$, e de largura, 6 p. Outro vaõ semelhante que se metia entre a mesma caza e propriedades da rua das Arcas que tem de comprimento do Norte pera o Sul, 46 p., e de largura, 6 p.» ${ }^{14}$. Corredores éstos a los que no se alude de forma tan expresa en la escritura de 1707, pero cuya existencia se apunta al describir las ventanas que daban luz por la parte del sur y del poniente a los corredores que cercaban los «camarotes» del tercer y segundo pisos: «En as costas do primeiro e segundo andar de camarotes [segunda y tercera plantas para nosotros] ha algumas janellas que cahem sobre chaõ desta medizaõ e seruentias deste dito patio, a saber: no andar de todo sima sobre a porta que fiqua ao sul, frontejra ao dito tablado, ha quatro janellas que fiquaõ fazendo frente ao sul, e pella parte do poente no mesmo andar ha duas janellas taõbem nas costas dos ditos camarotes que cahem sobre hum corredor descuberto per donde se seruem pera os ditos camarotes...» (NT, fol. 279ro y vo), ocurriendo lo mismo en el «primer andar de camarotes». La referencia a ese «corredor descuberto» en la parte occidental (aunque no se indica si estaba a nivel del suelo) y la necesidad de que las citadas ventanas diesen a un espacio abierto al cielo para que pudieran comunicar luz a los corredores de los «camarotes», nos inclinan a suponer la existencia de esos dos vanos, en 1707. Además, cuando se mide en cruz el Patio de Comedias, el brazo más largo se hace llegar desde la pared de fondo del vestuario hasta la puerta por donde se entra para los «asentos» y «fersuras», puerta que daría al vano sur, sin que por esta parte se haga entestar el Patio en las casas vecinas. Aunque las dimensio-

14 Archivo Nacional de la Torre do Tombo, Tombo da Cidade de Lisboa, 1755, fol. 71r.. En este caso se utiliza el palmo como medida de longitud, equivalente a $22 \mathrm{~cm}$. 


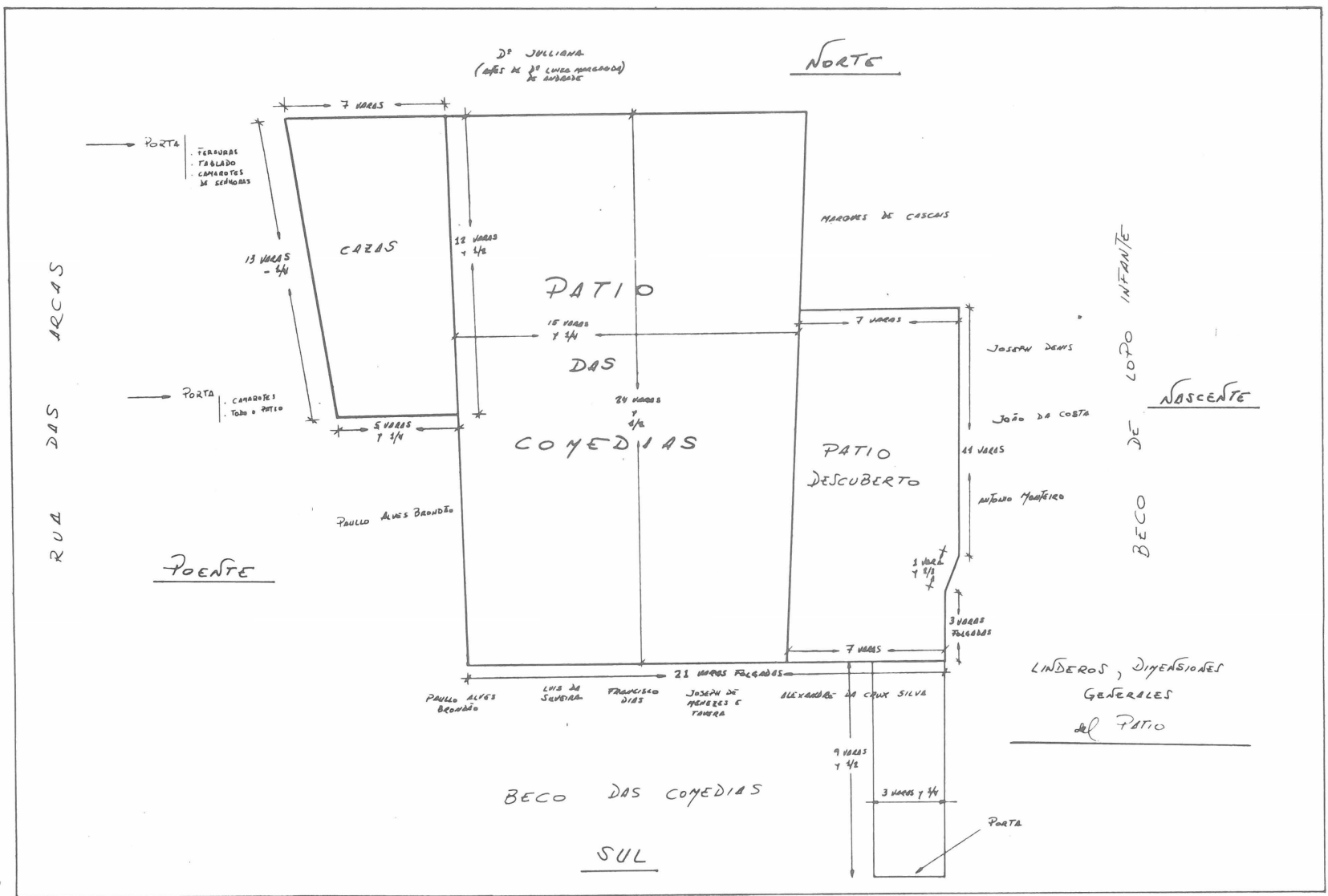

Lám. V. Linderos y dimensiones generales del Patio de las Arcas, y de las casas y patio descubierto anexos, en 1707. 
nes de esos dos vanos no se especifican en la escritura de 1707, éstas irían incluidas dentro de las totales de la propiedad del Hospital que se registra, porque, en este caso, los límites y medidas de ella se hacen llegar hasta la misma línea de unión con los predios colindantes.

\section{Dimensiones generales.}

Las dimensiones generales de la propiedad del Hospital cuyos límites hemos establecido, incluidos sus tres componentes - patio de comedias, casas anexas y patio descubierto también anexo-, eran (véase lámina V):

a) Por el Este, de norte a sur, quince varas y dos tercias. Este lado presentaba un quiebro hacia dentro, de levante para poniente, de una vara y dos tercias, las cuales, sumadas a las once que había hasta dicho quiebro y a las tres holgadas que lo seguían hasta un pilar de piedra - límite sur de este costado-, arrojaban la medida total indicada $\left(N T\right.$, fol. 275 ro y vo. ${ }^{15}$.

b) Por el Sur, de levante a poniente, veintiséis varas y una tercia. De ellas, veintiuna holgadas correspondían al testero sur del patio descubierto y del patio de las comedias, siendo las cinco restantes del lateral sur de las casas anexas (NT, fol. $276 \mathrm{r}^{\circ}$ ). .

c) Por el Oeste, de sur a norte, trece varas. Éstas eran sólo de la fachada de las casas anexas al Patio de Comedias que daban a la rua das Arcas, pertenecientes al Hospital, con declaración expresa de que por detrás de ellas la medida era mayor, como se verá cuando se mida el Patio de Comedias de forma aislada (NT, fol. $276 \mathrm{r}^{\circ} \mathrm{y} \mathrm{v}^{\circ}$ ).

d) Por el Norte, de poniente para levante, veintinueve varas y una cuarta (NT, fol. $276 v^{\circ}$ ). De ellas, siete pertenecían a las casas, siete al patio descubierto y las restantes al Patio de Comedias, como se especificará más adelante.

Pasando ahora a las medidas individuales de cada uno de estos tres componentes del «prazo» del Hospital que se registra, sus dimensiones eran:

CASAS
(NT, fol. 280vำ-281vํ)

PATIO DESCUBIERTO

(NT, fol. $281 v^{\circ}-282 r^{\circ}$ )

\author{
13 varas menos 1/4: poniente \\ 5 varas y $1 / 4$ : sur \\ 7 varas: norte \\ 12 varas y $1 / 2$ : levante \\ 16 varas: levante \\ 7 varas: norte \\ 7 varas: sur \\ Falta la medida del lado oeste
}

\footnotetext{
15 Las medidas en la escritura de 1707 se expresan en varas. Al final de ella, se advierte que dichas mediciones se hicieron «com hum cordel de sinquenta uaras de simquo palmos a uara, medida da cidade» (NT, fol. $283 \mathrm{r}^{\circ}$ ). Al tener el palmo $22 \mathrm{~cm}$., cada vara tiene una longitud de $110 \mathrm{~cm}$. Aunque en alguna ocasión pasaremos las medidas al sistema métrico decimal, las hemos conservado en varas para incurrir en la menor distorsión posible, pues a veces son fraccionarias o no exactas, como se puede apreciar en las que acabamos de citar.
} 


\section{PATIO DE COMEDIAS \\ $\left(N T\right.$, fol. $282 v^{\circ}$ )}

Medido por el medio en cruz, incluidas todas sus dependencias:

24 varas y $1 / 2$ : norte-sur

15 varas y $1 / 4$ : este-oeste ${ }^{16}$.

Además del «prazo» del Hospital, se incluye también en la medición un espacio ajeno que ponía en comunicación al Patio con la entrada que poseía por el Bêco das Comedias, cuyo uso aquella Institución tenía alquilado. Sus dimensiones en cruz eran: nueve varas y media de largo (norte-sur) y tres varas y cuarta de ancho (este-oeste) (NT, fols. 275v. $-276 \mathrm{r}^{\circ}$ ).

\section{Estructura del Patio de Comedias.}

Centrada ya nuestra mirada exclusivamente en el Patio de Comedias, conviene recordar, antes de emprender el estudio detallado de su estructura, su cambio de orientación respecto a su posición anterior: el tablado está ahora situado al norte, de cara al sur.

$\mathrm{Su}$ forma también había cambiado tras el incendio. A dicho cambio se aludía en el Livro de Receita de 1699-1700 (fol. 244r.) y en el romance del Conde de Tarouca, donde — recordemos - aquélla se describía así: «De meia laranja a forma / de seos camarotes vaj», recurriendo a una imagen frutal idéntica a la empleada en la escritura de 1707 que utilizamos: "el coal [patio em que se representaõ as comedias] esta em forma de huma meya laranja, com o tablado a parte do norte encostado as cazas da dita dona Julliana, fazendo frente ao sul» (NT, fol. 277r.). Dada la inscripción del Patio en un rectángulo y la situación del tablado (sobre el que existen aposentos, como veremos) en el extremo norte de los lados más largos, nos inclinamos por una forma de U u ovoide, en todo caso, mejor que completamente semicircular como apunta la imagen elegida para su descripción.

La altura del Patio era de tres pisos más el bajo, ocupados por «fersuras» (planta baja), «asentos» (planta primera) y «camarotes» (plantas segunda y tercera). Su estructura se apoyaba sobre veinte varales de hierro que armaban sobre un parapeto que corría alrededor del patio. Dicho parapeto, cubierto de piedra, servía de antepecho a las «fersuras». Sobre estos veinte varales se levantaban otros veinte en el primer piso, que sustentaban los aposentos del segundo - «primejro andar de camarotes»-, piso éste sobre el que había un tercero también de

16 Dada la importancia que tienen para nosotros las dimensiones del Patio de las Comedias, transcribimos completo el pasaje donde se indican: «Tem este dito patio em que se representaõ as ditas comedias de comprido de norte pera o sul, prinsipiando da parede que esta nas costas do uestuario ja atras confrontada the a porta per donde se entra pera asentos e fersuras, pello meyo uinte e quatro uaras e meya. E de nasente pera o poente pello meyo em crux tem quinze uaras e huma quarta. Esta he a medizaõ de comprimento e largura do patio em que se representaõ as comedias entrando nella tudo o atras confrontado e declarado do mesmo patio...» (NT, fol. 282vํ). Agradecemos a Juan Buendía la ayuda que nos ha prestado, desde el punto de vista arquitectónico, en la interpretación de los datos para la reconstrucción del Patio y en el trazado de las plantas. 
aposentos — «segundo andar de camarotes-, como ya hemos indicado. Literalmente dice así la escritura: el patio «esta fundado sobre uinte uaroens de ferro, os quais armaõ emsima de hum parapeito que corre todo em roda do patio, lajiado por sima o dito parapeito de pedra, donde estaõ asentados os ditos uaroens, o qual parapeito serue as fersuras de anteparo[...]. E sobre estes ditos uaroens uaõ outros vinte taõbem em roda e na mesma derejtura dos outros, de sorte que fiquaõ huns sobre outros no primejro andar de sobrados que serue todo de asentos [...], os quais uaroens sustentaõ o primejro andar de camarotes que fiqua sobre os ditos asentos [...]. E emsima deste sobredito primejro andar de camarotes ha outro que...» (NT, fols. 277r . $^{\left.-278 r^{\circ}\right)^{17}}$.

Como parece deducirse de la escritura, dichos «uaroens de ferro» darían la impresión de columnas de piedra, pues, rematados por capiteles de madera, estaban recubiertos de madera pintada, fingiendo ser piedra: «o coal todo [o patio] he pintado com seos capiteis de madejra sobre os ditos pilares e uarois de ferro, mostrando e serem de pedra fingida» (NT, fol. 283r. ). La alusión a los arcos que hace el Conde de Tarouca en su romance («Pello molde dos arcos / se debuxou tal galan / que a materia he de madeira / e a fineza de Cambraj») nos lleva a preguntarnos si las uniones entre los capiteles tendrían dicha forma. La cal tuvo que jugar un papel muy importante en la pintura del Patio, pues, en 22 de julio de 1726 , se pagan 10.460 reales portugueses por su limpieza y blanqueo (AHSJ, Livro de Despesa, 1725-26, fol. 176v․). El período del verano de este año debió de aprovecharse para remozar dicha pintura, ya que unos días antes, el 15 de junio, se habían abonado 7.800 rs. a Jozeph Teyxeira "por obras de seu ofiscio de pintor no patio das comedias» (Idem, fol. 173v. ).

Respecto al suelo del patio y de los corredores bajos, sabemos por un documento de 1. de septiembre de 1717 que estaba empedrado, al menos en esa fecha. Ese día se anotan en el Livro de Despesa del Hospital 17.780 reales portugueses, que se pagaron a «Francisco Gonçalvez, calceteiro de calçadas, por calsar o pateo das comedias e seus corredores em que fez vinte a e tres braças de calçada, pondo o dito a pedra a preço cada braça de setecentos e setenta reis, a qual calsada foy medida pelos Maestros Manuel Antunes e Manuel das Neues...» (AHSJ, Livro de Despesa, 1717-18, fol. 190v: ${ }^{18}$.

17 Recordemos que sobre veinte basas de piedra se organizaban también las galerías del corral de Toro, sobre las que «descargarían — como indica J. R. Nieto González- otras tantas columnas de negrillo rematadas con zapatas», esquema que se repetía en el primer y segundo pisos (J. R. Nieto González, «Trazas para una casa de comedias: 1605», Studia Philologica Salmanticensia, IV, 1979, pp. 221-32, pp. 223-24). E, igualmente, en el Corral del Coliseo de Sevilla, tras la reconstrucción de 1614 , los dos primeros pisos de aposentos y de galerías cubiertas (de los tres que poseía sobre el bajo) reposaban sobre veinte columnas de mármol coronadas por capiteles de estilo dórico (Cf. Jean Sentaurens, Séville et le théâtre de la fin du Moyen Âge a la fin du XVII ${ }^{e}$ siècle, Bordeaux, Presses Universitaires, 1984, 2 vols., vol. I, p. 308.

18 Este dato y esta partida también los recoge J. Gonçalves Ribeiro Guimarães, art. cit., Jornal do Commercio, n. 6585,16 de octubre de 1875 . 


\section{Planta baja.}

La planta baja (lámina VI), además de la localidad del patio, tenía dieciocho «fersuras [...] todas em roda» que lo cercaban, cuyas dimensiones no se indican (NT, fol. 277r.). Las forçuras eran, como anota J. M. A. Nogueira, «uns camarotes pequenos, que serviam de base aos das ordens superiores; correspondiam ao que hoje [1866] chamamos frisas...» ${ }^{19}$. Este número de aposentos —dieciocho- no coincide con los veinte que se registran en esta planta baja cuando se inaugura el Patio, el 12 de abril de 1700: «No primeiro andar [bajo para nosotros] ha vinte aposentos, que saõ logeas dos maes, a que chamaõ forçuras» ( Livro de Receita, 1699-1700, fol. 244ro). A ellos se accedía por puertas que daban a un corredor que los circundaba por detrás. Dado que desde las «fersuras» el público veía sentado la representación, ¿se hallarían éstas a una cierta altura sobre el nivel del suelo del patio para favorecer la visibilidad desde ellas?. Aunque la escritura sitúa el corredor de acceso a éstas «ao niuel do dito patio per baixo do sobrado que serue de asentos» (NT, fol. 277rº), ¿no podría tratarse de una pequeña elevación que no impidiera considerarlas a dicho nivel? De lo contrario, resulta difícil imaginar la visión que los espectadores disfrutarían desde este tipo de asientos. No obstante, Ribeiro Guimarães, a quien le parece que las forçuras quedaban muy bajas, recuerda todavía «ouvir chamar ás frisas enferninhos, denominação de certo originada pelo facto de serem baixas» ${ }^{20}$.

Sobre el patio como localidad, un espacio amplio que suponemos ocupado por espectadores como en la etapa anterior, nada dice la escritura de 1707, lo cual no resulta extraño dada la naturaleza de la misma. Lo es, en cambio, el hecho de que cuando en abril de 1700 se registran «los aposentos e lugares» de que se compone el Patio, no se haga la menor alusión al respecto (Livro de Receita, 1699-1700, fol. 244ro). Si en el patio había algún tipo de asientos, ¿por qué no se indica?. ¿Verían desde él los espectadores de pie la representación?. Pero, si en la etapa anterior al incendio parecen haber existido ${ }^{21}$, ¿por qué se iban a suprimir ahora, cuando sabemos que las condiciones de estancia en el Patio mejoran tras su reedificación? Preguntas éstas que por el momento han de quedar sin respuesta ${ }^{22}$. Lo que sí sospechamos es que esta zona - el patio como localidaddebió de ser empleada para la escenografía, como deja entrever este pasaje del contrato de arrendamiento del Patio de Comedias por diez años, a partir del 16 de octubre de 1737, a João de Villanova, Luis Trinite y Antonio Forestier —el fiador-(B N L, Ms. 31, n. 23): al finalizar el mismo, dice el contrato, «so pode-

19 J. M. A. Nogueira, «Archeologia do theatro portuguez (1588-1762)», Jornal do Commercio, n. 3737,6 de abril de 1866 .

20 José Gonçalves Ribeiro Guimarães, «Memorias para a historia dos theatros de Lisboa», Jornal do Commercio, n. 6585, 16 de octubre de 1875.

21 Véase Mercedes de los Reyes Peña y Piedad Bolaños Donoso, «El Patio de las Arcas de Lisboa a finales del siglo XVII. Comparación con el corral castellano», art. cit., en prensa.

22 Ribeiro Guimarães se inclina, con ciertas reservas, por la ausencia de asientos: «Ao que parece - dice-, os espectadores na platéa estavam em pé; os assentos, que eram uma galeria, ficavam, como se viu, por cima das frisas...» (Jornal do Commercio, no 6585, 16 de octubre de 1875). 


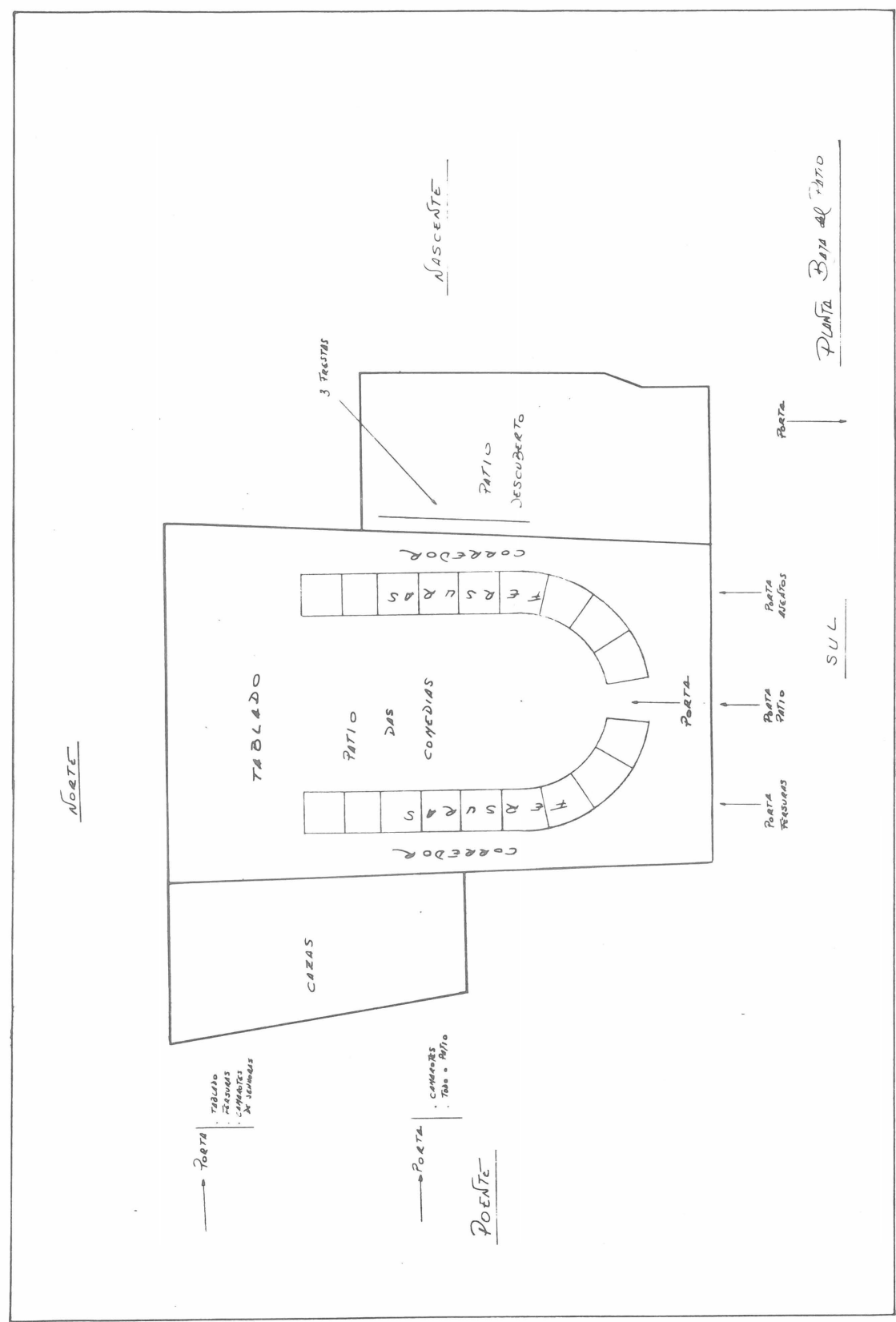

Lám. VI. Planta baja del Patio de las Arcas, en 1707. 
raõ os dittos rendatarios tirar o teathro que fizerem para a reprezentaçam e tudo o mais que fizerem na area do patio e os bastidores, com tanto que naõ haja damno nem nos camarotes a que chamaõ Forçuras, nem nos muros delles; porem no cazo que o Hospital queira o ditto theatro e estas obras que respeitaõ a area que saõ separadas dos camarotes, corredores, telhados e madeiramentos delles, elles rendatarios as naõ poderaõ tirar querendo-as o Hospital pello preço em que entam se avalliarem...»(fols. $4 v^{\circ}-5 v^{\circ}$ ). Aunque no sabemos qué tipo de obras eran ésas, el contexto inclina a ponerlas en relación con la escenografía.

\section{Planta primera.}

El primer piso (lámina VII) era una galería corrida en su mayor parte, ocupada por cinco gradas alrededor de todo el patio, que sólo en sus extremos, ya sobre el tablado, aparecía dividida en aposentos: cuatro para hombres, a la derecha (levante); y tres para mujeres, a la izquierda (poniente) (NT, fol. 277ro y vo.). En el Livro de Receita de 1699-1700, donde se especifica el número de gradas, no se registran más que seis aposentos: «O segundo andar [primer piso para nosotros] tem na altura do tablado seis camarotes, e o mais andar he de assentos gerais com sinco degraos em roda de todo o pateo» (fol. 244r.). "Camarotes» éstos que, dada su posición, serían muy apetecidos por el público, como sugiere Matos Sequeira: «Estou daqui a futurar que as mulheres — damas de tômo-e os estroinas fidalgos, tinham aqui os seus poisos mais certos. Viam-se melhor as comediantes e viam-se melhor uns aos outros» ${ }^{23}$. Desde sus bancos - «escanos nobilíssimos das ilhargas do tablado, coloridos de bancais de armas», en palabras de Júlio Dantas ${ }^{24}$-, los nobles admirarían y disfrutarían con las actrices, compensando, con «a vaidade tumultuosa dos portugueses», cumplidamente sus favores: «a dobrões de oiro cada sorriso, a patacas da prata cada palavra, a mãos cheias de diamantes cada beijo...», como apunta el investigador citado ${ }^{25}$.

\section{Planta segunda.}

El segundo piso (lámina VIII) estaba dividido en veintiún aposentos, cuyas dimensiones no se indican: «primejro andar de camarotes que serqua o patio em roda», dándoles acceso un corredor posterior (NT, fol. $277 \mathrm{v}^{\circ}$.). Dos de ellos, uno sobre el tablado y otro fuera de él, pertenecían al Marqués de Cascais, D. Luis Alves de Ataide de Castro e Souza, a los que entraba por sus casas del Bêco de Lopo Infante (NT, fols. $277 \mathrm{v}^{\circ}-278 \mathrm{r}^{\circ}$ ). Recordemos que son los dos aposentos que le concedió la Mesa de la Misericordia a cambio de los doce palmos que aquél

23 Gustavo de Matos Sequeira, Teatro de outros tempos. Elementos para a História do Teatro Português, Lisboa, 1933, p. 103.

24 Júlio Dantas, O amor em Portugal no século XVIII, Porto, 1916, p. 145.

25 Ídem. 


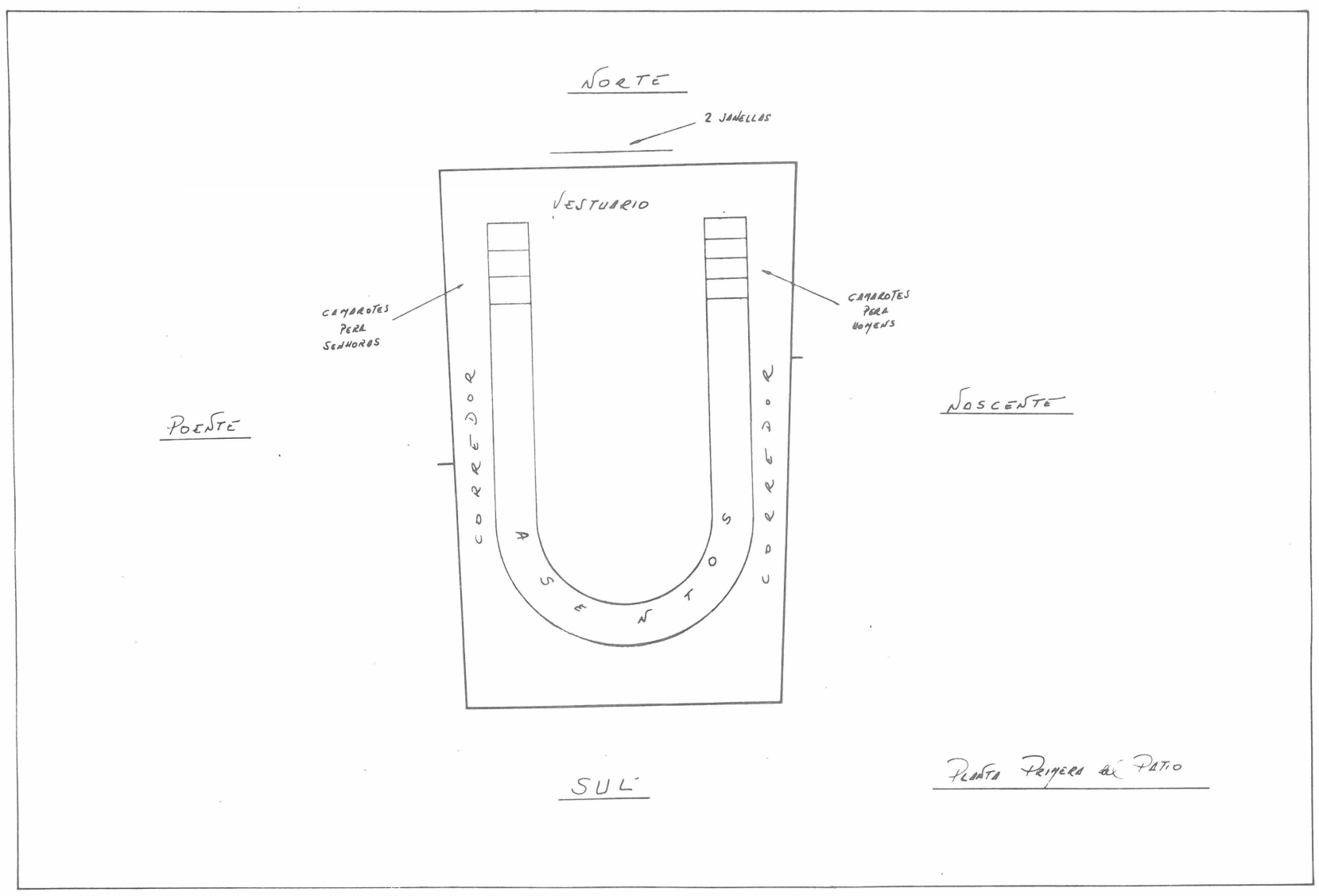

Lám. VII. Planta primera del Patio de las Arcas, en 1707. 
cedió para la ampliación del Patio, en 1699. Por el contrato de arrendamiento de 1737, ya citado, sabemos que estos dos aposentos quedaban a veces impedidos por la escenografía. En esos casos, el Hospital —igual que deberán hacer después los nuevos arrendatarios - proporcionaba al Marqués dos en otro sitio: «e todas as vezes que estes [os dous camarotes que tem no pateo das comedias o Excellentissimo Marques de Cascaes] forem impedidos com alguma maquina que for perciza para a representaçaõ, seraõ elles rendatarios obrigados a lhe dar dous camarotes em outro citio como sempre foi vzo e custume, e isto tantas quantas vezes houvera semelhante impedimento» (BNL, Ms. 31, n. 23, fol. 5r.).

Suponemos que en esta segunda planta sólo existía un camarote a cada lado sobre el tablado. De esta forma, se mantendría la correspondencia de las paredes divisorias de los camarotes con los varales de hierro de las plantas baja y primera. Nos queda por saber si la capacidad de este camarote único sería semejante - así lo hemos supuesto- a la de los camarotes correspondientes sobre el tablado de la primera planta. Idéntica solución ofrecemos para la siguiente.

\section{Planta tercera.}

El tercer piso (lámina VIII) estaba igualmente dividido en veintiún aposentos — «segundo andar de camarotes»- a los que se entraba por un corredor posterior ${ }^{26}$. Uno de ellos, situado en la parte occidental del Patio, era del Hospital y utilizado por «os fidalgos da caza da fazenda delle», por lo que no se alquilaba (NT, fol. 278r. y vo.).

\section{Escenario.}

A pesar de su tardía fecha de reedificación, el escenario de las Arcas sigue respondiendo en su estructura al del corral castellano, sin incorporar, como permiten suponer los datos que poseemos, las conquistas escénicas de los coliseos italianos. Así, por ejemplo, la existencia de aposentos sobre el tablado impide hablar de telón de boca y del consiguiente aislamiento del lugar escénico, que en el Patio de las Arcas quedaba rodeado de espectadores por tres de sus lados. Por otra parte, la situación del vestuario detrás de la pared de fondo del tablado y la disposición de ésta con dos galerías o corredores, una a nivel del segundo piso y otra del tercero, completan la semejanza del escenario de las Arcas con el del corral castellano, proporcionándole los tres niveles horizontales que se documentan en los madrileños: «en este primejro andar de camarotes [segundo piso del Patio] —dice la escritura de 1707-, corre huma baranda ao niuel delles sobre o tablado, fazendo frente a dita porta per donde se entra pera o patio que fiqua

26 Recordemos que el corral de Toro tenía también dos pisos de aposentos [primero y segundo] con un total de 42 , como ocurría en las Arcas. La superficie de aquéllos era de $2,81 \mathrm{~m}^{2}$, haciéndolos capaces al menos para cuatro personas (Cf. J. R. Nieto González, «Trazas para un corral de comedias: 1605» art. cit., p. 244). 


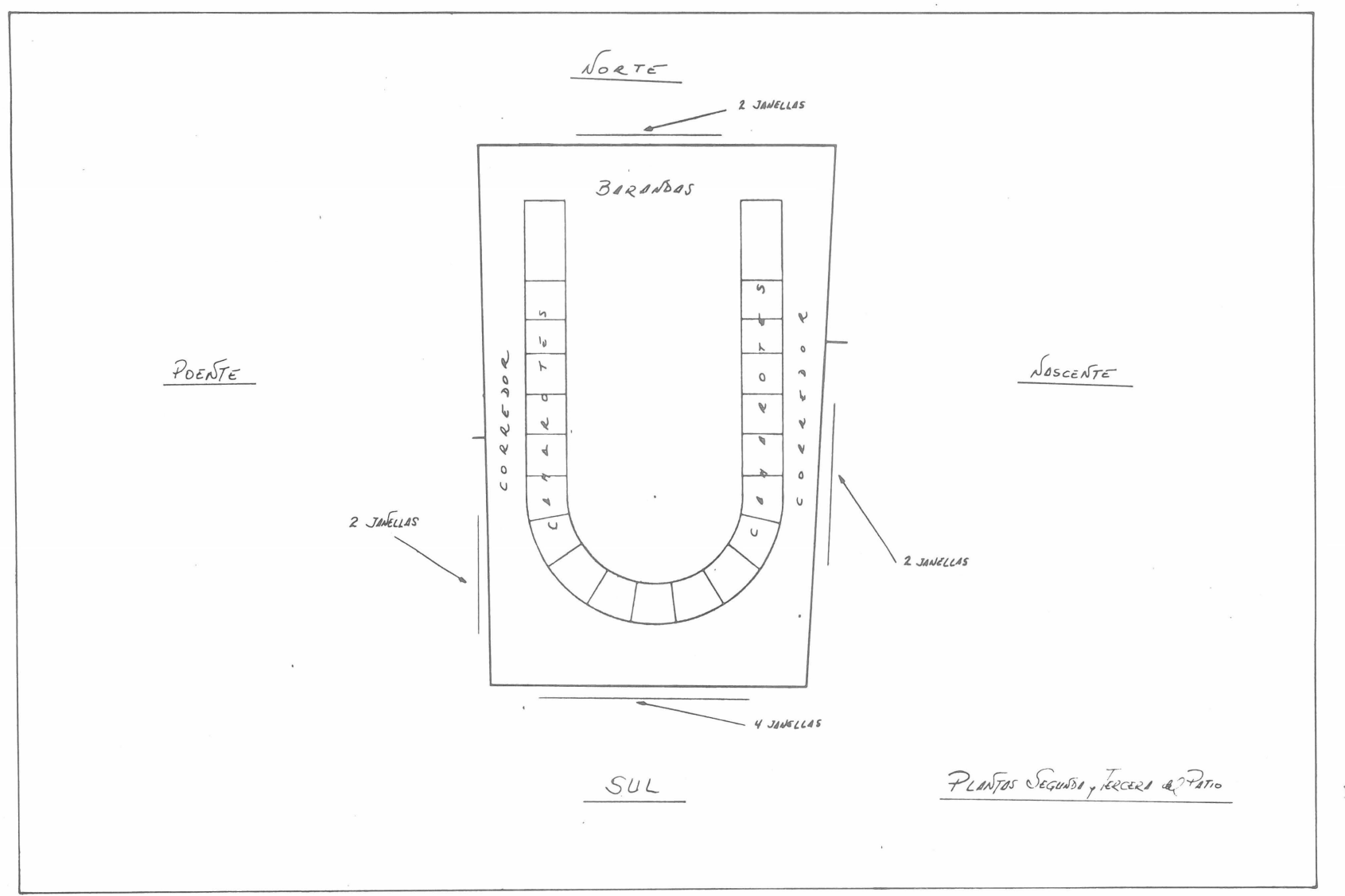

Lám. VIII. Plantas segunda y tercera del Patio de las Arcas, en 1707. 
ao sul como fiqua dito, encostada sempre as cazas da dita dona Julliana [...]; en este andar [segundo de «camarotes» y tercer piso del Patio] ha outra baranda emsima da outra que esta no primejro andar, na mesma forma» (NT, fol. 278r. y vo.) ${ }^{27}$. Estas galerías debían de cubrir el vestuario, porque sus espaldas, igual que las de éste, entestaban en la propiedad vecina —las casas de doña Julliana-. En esta pared limítrofe había varias ventanas, que aparecen así descritas: «En as costas das ditas barandas sobre o tablado, fiquaõ duas janellas pequenas gradadas de ferro na parede das cazas da dita dona Julliana, pera o parte do norte, quazi ao niuel do dito tablado; e emsima destas ha outras duas quazi ao niuel da primejra baranda, taõbem com grades e do mesmo tamanho; e emsima tem outras duas ao niuel da segunda baranda, na mesma forma que as outras; e em todo sima ha duas janellas nesta mesma parte a forma de claraboyas, pellas quais se comuniqua lux as sobreditas barandas e preparasaõ pera as aparensias das comedias» (NT, fol. 278v? ). Por su posición y funcionalidad parece lógico suponer que estas dos últimas ventanas estarían situadas en el techo de la segunda galería, más bien que en la parte alta de su pared posterior.

En cuanto al tablado, desconocemos su altura y dimensiones. No obstante, con los escasos datos que poseemos haremos algunas consideraciones. Como ya hemos indicado, tampoco sabemos si en el Patio había algún tipo de asientos (excluidos los de las «fersuras» que lo rodeaban) tras los cuales parte del público viera de pie la representación, como supusimos para la etapa anterior, o si todos los espectadores allí ubicados la contemplarían de pie. De cualquier forma, en ambos casos, la presencia de personas de pie en el patio, nos obligaría a situar el tablado a una altura semejante a la que barajábamos para antes del incendio: entre $1,54 \mathrm{~m}$. y $1,68 \mathrm{~m}^{28}$. Pero también podríamos preguntarnos si quedaría al nivel del suelo del primer piso, pues en esta etapa del Patio de las Arcas las dos galerías o corredores del fondo del tablado estaban al nivel del segundo y tercer pisos, permitiendo perfectamente su altura la salida de los actores desde el vestuario. De esta forma, los aposentos del primer piso que se encontraban en los laterales del escenario podían estar a su mismo nivel. Recordemos que, en el $\mathrm{Li}$ vro de Receita de 1699-1700, se dice que están «na altura do tablado» (fol. 244r\%), expresión ambigua que puede indicar tanto su ubicación dentro de él como su situación a su nivel. Respecto a la posibilidad de que dicha altura resultase excesiva, conviene advertir que el tablado del Corral de la Montería de Sevilla estaba

27 Sobre la funcionalidad de estas galerías, diferimos por completo de Matos Sequeira. Para él, «estes passadiços serviriam de passagem ao público de um lado para outro do Pátio, talvez por que o corredor de serventia dos camarotes das duas últimas ordens fôsse interrompido, ao fundo, por qualquer intromissão de muro ou prédio vizinho, ou, propòsitadamente, em atenção ao preceito tradicional da separação dos sexos» (Gustavo de Matos Sequeira, Teatro de outros tempos..., ob. cit., pp. 104-105). Para nosotras, estaban al servicio de la escenografía, empleándose para las escenas de balcón, de muralla, de torre o de cielo, como en el escenario del corral castellano (Véase David Castillejo y Otros, «IV. Uso del escenario», en El corral de comedias. Escenarios, Sociedad. Actores, Madrid, Concejalía de Cultura del Ayuntamiento, 1984, pp. 81-118).

28 Véase Mercedes de los Reyes Peña y Piedad Bolaños Donoso, «El Patio de las Arcas de Lisboa a finales del Siglo XVII...», art. cit., en prensa. 
a 2,5 m. sobre el suelo del patio, altura a la que se levantaba el primer piso ${ }^{29}$, pudiendo estar el de las Arcas incluso menos elevado, si la altura de éste hubiera sido menor.

Sobre las dimensiones del tablado nada se indica en la escritura de $1707 \mathrm{y}$, debido al desconocimiento de las medidas de las distintas dependencias del Patio inscritas en ese rectángulo que lo enmarcaba (corredores, aposentos y vestuario), silenciadas totalmente en dicho documento, resultan imposibles de establecer. No obstante, la presencia de esos cuatro y tres «camarotes» a ambos lados del tablado en el primer piso habla, en el caso de que todos estuvieran por completo - como parece- dentro de él, de una profundidad mayor que la atribuida por John J. Allen al escenario del Corral del Príncipe (14,5 pies de fondo, es decir, 4 m.) ${ }^{30}$ y mayor también que la de la zona de representación del Corral de Alcalá de Henares $\left(5 \mathrm{~m} \text {. de fondo hasta el 'balcón de las apariencias }{ }^{6}\right)^{31}$.

Este escenario que acabamos de describir, igual que le ocurría a su modelo castellano, no era en absoluto el adecuado - a pesar de su factura de nuevo cuño y su tardía fecha de construcción- para incorporar el empleo del decorado en perspectiva, a través de bastidores escalonados, otra de las grandes conquistas de la escenografía renacentista italiana. Aunque John E. Varey defienda su uso en los corrales ${ }^{32}$ y en el contrato de arrendamiento del Patio de las Arcas de 1737, se hable de 'teatro que hicieren para la representación', de 'bastidores ${ }^{6} 33$ y de una probable utilización del patio para la escenografía - lo que ampliaría el espacio escénico-, como señalábamos más arriba, hay una serie de inconvenientes que vencer, dada la estructura del escenario (carencia de telón de boca, aposentos laterales sobre el tablado, cubrimiento de los bastidores por sus extremos laterales y superior, falta del espacio necesario para las mutaciones, imposibilidad de disfrutar de la perspectiva por los espectadores situados en las locali-

29 Cf. Jean Sentaurens, Séville et le théâtre de la fin du Moyen Âge à la fin du XVII ${ }^{e}$ siècle, ob. cit. vol. I, pp. 328-29 y 327.

30 Cf. John J. Allen, The Reconstruction of a Spanish Golden Age Playhouse. El Corral del Príncipe (1583-1744), Gainesville, University Presses of Florida, 1983, p. 39. En «Hacia una revalorización del Corral de Comedias de Almagro» (Journal of Hispanic Philology, VII, n. 3 (1983), pp. 201-211), el citado investigador reduce ligeramente esta medida, al darle al tablado del Príncipe 13,5 pies de profundidad.

31 Cf. Mercedes Higueras Sánchez-Pardo, Juan Sanz Ballesteros y Miguel Angel Coso Marín, «Alcalá de Henares: un nuevo corral de comedias», en Edad de Oro, V, Madrid, Universidad Autónoma, 1986, pp. 73-106, p. 90.

32 Véase su comunicación «El influjo de la puesta en escena del teatro palaciego en los corrales de comedias», presentada en el Simposio Internacional «El teatro español a fines del siglo XVII» (Amsterdam, 6 al 10 de junio de 1988), actualmente en prensa en sus Actas, que conocemos por su exposición oral en el mismo.

33 Siempre para advertir que los arrendatarios se los podrían llevar al finalizar el contrato (BNL, Ms. 31, no 23, fols. $3 \mathrm{r}^{\circ}$, $4 \mathrm{v}^{\circ}$. $-5 \mathrm{r}^{\circ}$. y $14 \mathrm{r}^{\circ}$ ). Estas menciones a los bastidores no suponen su utilización escalonada para proporcionar un decorado en perspectiva. Se podría tratar, simplemente, de los lienzos sobre marcos de madera empleados en la escenografía de las comedias, con un uso semejante al que se aprecia en esta acotación de José de Cañizares: «(Descúbrense dos bastidores de estantes de libros, como de facultad grande, sillas y una mesa con libros» (en Abogar por su ofensor, BAE, XLIX, p. 555. Citamos por David Castillejo y Otros, El corral de comedias. Escenarios. Sociedad. Actores, ob. cit., p. 87). 
dades laterales más próximas al escenario...), que hacen difícil imaginar el empleo de este tipo de decorado en el Patio lisboeta.

\section{Ventanas y puertas del Patio.}

La escritura de 1707 describe detalladamente una serie de ventanas que daban luz a los corredores que, por detrás, daban acceso a las «fersuras» y «camarotes»:

a) En la planta baja, el corredor que cercaba las «fersuras» tenía tres ventanas — «frestas»- en la parte oriental, que daban al patio descubierto. La parte occidental de dicho corredor no poseía ninguna — recibía la luz que se le comunicaba del patio, según indica el documento, lo cual resulta difícil de entender-, pero tenía al final una salida que daba a una de las puertas del Patio hacia la rua das Arcas. En la parte sur, tampoco había ventanas, sino tres puertas que conducían al «patio», los «asentos» y las «fersuras». La primera debía ser central — «que fas frente ao dito tablado»- y las otras dos laterales, pues la tercera «fiqua ao poente, da parte ezquerda» (NT, fols. 278v‥279r. $)$.

b) El corredor de los aposentos del tercer piso tenía cuatro ventanas hacia el sur; dos hacia el oeste, «que cahem sobre hum corredor descuberto per donde se seruem para os ditos camarotes», en cita ya utilizada; y dos hacia levante, que daban al patio descubierto ( $N T$, fol. 279r. y vo ). Idénticas ventanas presentaba el corredor de los aposentos del segundo piso, «as quais janellas — se especifica en la escritura-, humas e outras, todas seruem de comunicar lux aos corredores que serquaõ os camarotes em roda» (NT, fol, 279v $\left.{ }^{\circ}\right)$.

Debido al desconocimiento de la posición exacta de las ventanas y las puertas, no hemos podido localizar con precisión aquéllas en los planos y debemos tomar con precaución la ubicación dada a éstas.

\section{Entradas al Patio desde la calle.}

El Patio tenía tres entradas desde la calle: una para el Bêco das Comedias y dos para la rua das Arcas. Éstas son, al menos, las que se describen en la escritura de 1707 al tratar este punto concreto (NT, fols. 279vㅇ-280ro). Por ello, extraña que, cuando se localiza en la misma escritura el Patio de las Comedias, se hable de una puerta al Bêco de Lopo Infante: «o qual [o patio das comedias] fiqua interior ao dito bequo das Comedias, sem embarguo de que pera ahy tem porta, como tambem no de Lopo Infante e a dita rua das Arquas» (NT, fol. 271ro), sin que aparezca después ninguna otra referencia a ella.

Desde la puerta situada en el Bêco das Comedias, se llegaba al Patio a través de un pasaje cuyo uso tenía alquilado el Hospital, por serle ajeno, como ya hemos indicado. La especificación «per donde entraõ todas as pessoas que as uã̃ uer [as comedias]», aplicada a esta puerta (NT, fol. 277r.), muestra que daba acceso a todas las localidades del Patio. De las dos puertas a la rua das Arcas, 
una estaría en la parte norte de la fachada de las casas del Hospital anexas al Patio ${ }^{34}$ y la otra en el extremo sur. Por la primera, se entraba a los «camarotes das fersuras e tablado e camarotes de senhoras», sirviendo la segunda para el acceso a los «camarotes» $\mathrm{y}$ «communiquasaõ de todo o patio» (NT, fol. 280r ${ }^{\circ}$ ). Esta última puerta tenía un corredor en la entrada, que desembocaba en un patio pequeño descubierto - «patim»-. Desde él, se subía por una pequeña escalera de piedra que quedaba al poniente, «nas costas das cazas do dito Paullo Alues Brondaõ e estalagens do dito Francisco Dias» (Ídem) ${ }^{35}$.

\section{Cubierta del Patio.}

El Patio, tras su reedificación, debió de quedar totalmente cubierto, como lo estaba antes del incendio de 1697. Recordemos que de él sale mejorado, por lo que el techo no podía faltar. Además, en documentos posteriores se alude a importantes obras realizadas en la cubierta (AHSJ, Livro de Despesa, 1714-15, fols. 208r. $-209 r^{\circ}$ ) y a arreglos necesarios en los tejados («Contrato de arrendamiento por diez años, a partir de octubre de 1737», BNL, Ms. 31, n. 23). Por otra parte, dada la estructura del Patio - una galería corrida en la mayor parte del primer piso y aposentos en los restantes-y la ausencia en él de telón de boca, el techo era el único lugar apropiado para esa pintura del pelícano - símbolo de la benéfica labor realizada por el Hospital con los pobres enfermos-y de las quinas de Portugal, elogiosamente descrita por el Conde de Tarouca en su romance a D. Felipe de Sousa.

Respecto al sistema de iluminación del Patio, las únicas referencias que tenemos son las relativas a las ventanas que daban luz a los corredores de las «fersuras» y «camarotes», y a las dos que, como especie de claraboyas, iluminaban las dos galerías o corredores sobre el tablado, como ya hemos visto.

\section{El Patio de las Arcas y el Corral de la Montería de Sevilla.}

El nuevo estado del Patio de las Arcas tras el incendio nos recuerda bastante, salvadas todas las diferencias, al que presentaba el sevillano Corral de la Montería, construido en 1626, si bien éste era más amplio (véase lámina IX) ${ }^{36}$. Todo

34 El tipo de localidades a las que esta puerta daba entrada, como veremos a continuación, y el hecho de que al final del corredor de las «fersuras» de la parte occidental hubiera una salida a una de las puertas de la rua das Arcas, nos ha permitido colocar dicha puerta en esta posición.

35 Desconocemos qué «estalagens» eran éstos. Por la posición de la puerta, cuyo corredor de entrada conducía al patio, y el reducido tamaño de éste, dada su denominación — «patim»—, no podía tratarse de los que Francisco Dias poseía al sur del Patio.

36 Se inscribía en un rectángulo de $35 \times 25$ metros, con un patio que tenía $23 \mathrm{~m}$. de largo por $16 \mathrm{~m}$. de ancho, sobre el que avanzaba el tablado 3,08 m. (Cf. J. Sentaurens, Séville et le théâtre de la fin du Moyen Âge à la fin du XVII ${ }^{e}$ siècle, ob. cit. vol. I, pp. 323 y 328-29). Recordemos que el rectángulo en que estaba enmarcado el Patio lisboeta con todas sus dependencias, medido en cruz, tenía $26,95 \mathrm{~m}$. de longitud por $16,77 \mathrm{~m}$. de anchura. 


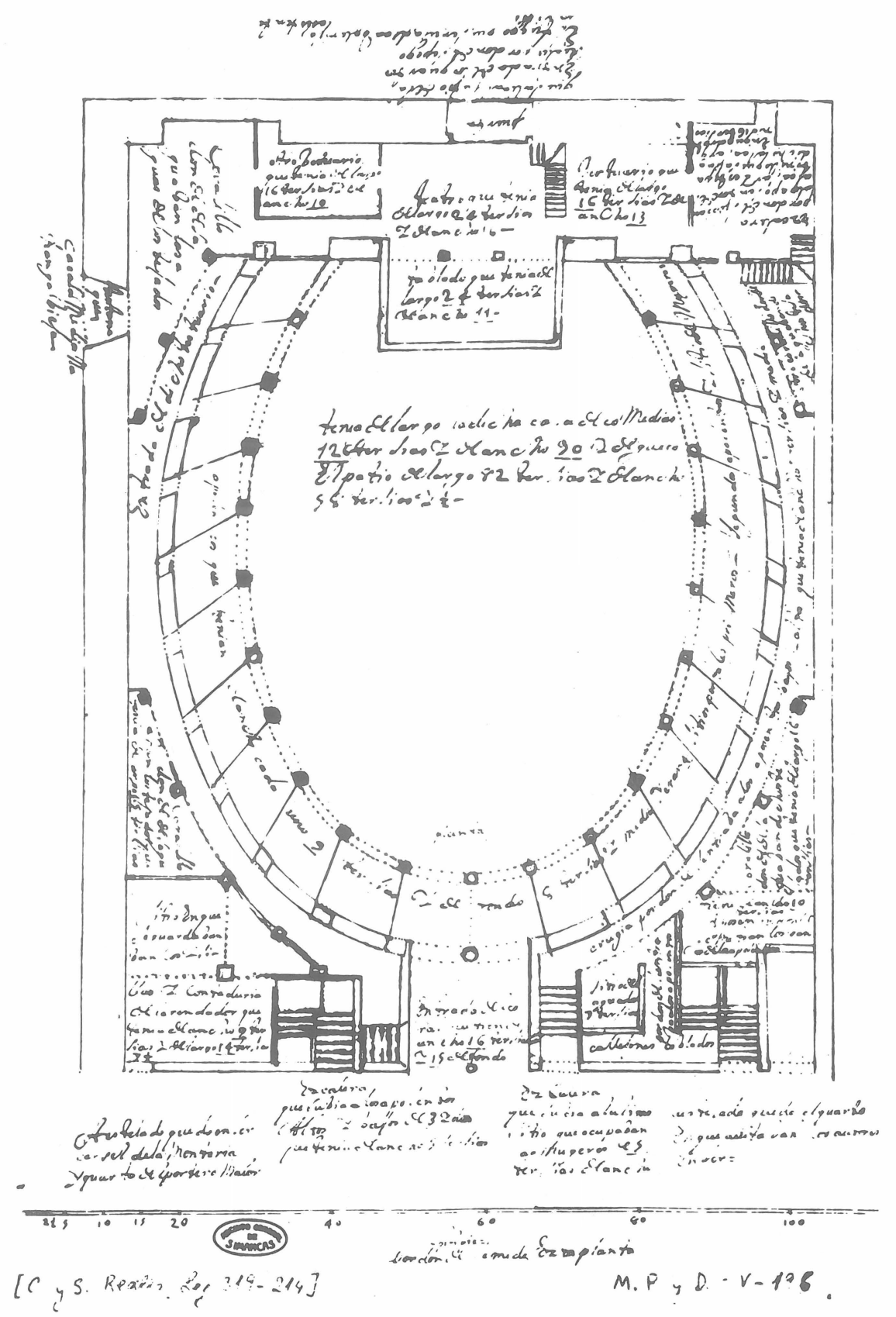

Lám. IX. Plano del Corral de la Montería (reproducido de Jean Sentaurens, Séville et le théâtre de la fin du Moyen Âge à la fin du XVII ${ }^{e}$ siècle, ob. cit., vol. I, p. 325). 
cubierto y de forma ovoide, sus tres niveles de galerías reposaban sobre veintiún pilares (veinte en las Arcas), con dos órdenes de veintidós aposentos en el primero y segundo pisos (veintiuno en las Arcas, en el segundo y en el tercero) y una galería sin divisiones en la tercera planta (primera en las Arcas). La elegancia de sus líneas y la originalidad de su planta queda de manifiesto en estas palabras de Jean Sentaurens: «Les trois galeries couvertes entourent harmonieusement l'aire centrale, sur laquelle s'avance la scéne; l'élégance des colonnades où alternent le bois et la pierre, la délicatesse des balcons de fer forgé, la blancheur du front de scène soigneusement badigeonné de lait de chaux, la finesse de lambris qui recouvrent les appartements intérieurs, l'ocre-jaune de la terre battue qui tapisse la cour, le rouge des briquettes dont sont pavées les loges, celui de tuiles canal qui composent la toiture, sont autant de preuves du goût discret avec lequel a été conçu le théâtre» ${ }^{37}$. Un bello corral, en suma, que, si había superado en comodidades para el público, acústica y estética a los anteriores corrales de Sevilla, como advierte Sentaurens, seguía ofreciendo, sin embargo, las mismas condiciones que aquéllos para la puesta en escena ${ }^{38}$.

Características éstas que pueden suscribirse a la letra para el Patio de las Arcas. Si hemos de creer los elogios del Conde de Tarouca, el nuevo Patio había superado con creces al antiguo. Estéticamente parece más ciudado y su nueva forma favorecería, sin duda, la visión del escenario por los espectadores. Pero, igual que ocurrió en la Montería, tampoco se introdujeron en su escenario innovaciones que mejoraran las condiciones escenográficas, presentando, como aquél, un escenario similar al del corral castellano.

37 Cf. Ídem, pp. 323-26.

38 Cf. Ídem, p. 333. 

